\title{
Análise ergonômica do ambiente construído: estudo de uma escola pública de ensino fundamental em Fortaleza
}

\author{
Ergonomic analysis of the built environment: study of a public \\ elementary school in Fortaleza
}

\begin{abstract}
ALANA VASCONCELOS
Mestranda em Arquitetura e Urbanismo; PPGAU+D-UFC; alanaavasconcelos@gmail.com

AURISEU PINHEIRO

Mestranda em Arquitetura e Urbanismo; PPGAU+D-UFC; auriseunogueira@gmail.com

VIRNA OLIVEIRA

Graduanda em Arquitetura e Urbanismo; UFC; virnamoliveira@arquitetura.ufc.br

KARINA LIRA

PhD, Professora associada da UFPB; UFPE/CE/DPOE; karina@ufc.br
\end{abstract}

ZILSA SANTIAGO

Doutora, PPGAUD/Universidade Federal do Ceará, zilsa@arquitetura.ufc.br

\section{RESUMO}

Este artigo tem como propósito apresentar o estudo realizado em uma escola pública da rede municipal de ensino da cidade de Fortaleza-CE, a partir da aplicação da Metodologia Ergonômica para o Ambiente Construído - MEAC, proposta por Villarouco (2008). As etapas seguidas para realização do estudo foram: Análise Global do Ambiente, Identificação da Configuração Ambiental, Avaliação do Ambiente em Uso, Percepção Ambiental do Usuário e Diagnóstico Ergonômico do Ambiente. Nesta ultima etapa foi elaborado um diagnóstico destacando alguns problemas encontrados e relacionando com recomendações para a adequação do espaço aos seus usuários, a fim de propor melhorias aplicáveis aos ambientes. Os resultados obtidos após a análise direcionam para a necessidade de melhorias em alguns aspectos, sobretudo relacionadas a conforto e acessibilidade. Por fim, destacam-se como pontos cruciais as interações entre as variáveis do ambiente construído e a realização das atividades dos usuários, a fim de alcançar os ideais definidos pelos estudos da Ergonomia.

PALAVRAS-CHAVE: ergonomia; escola; MEAC; percepção pelos usuários. 


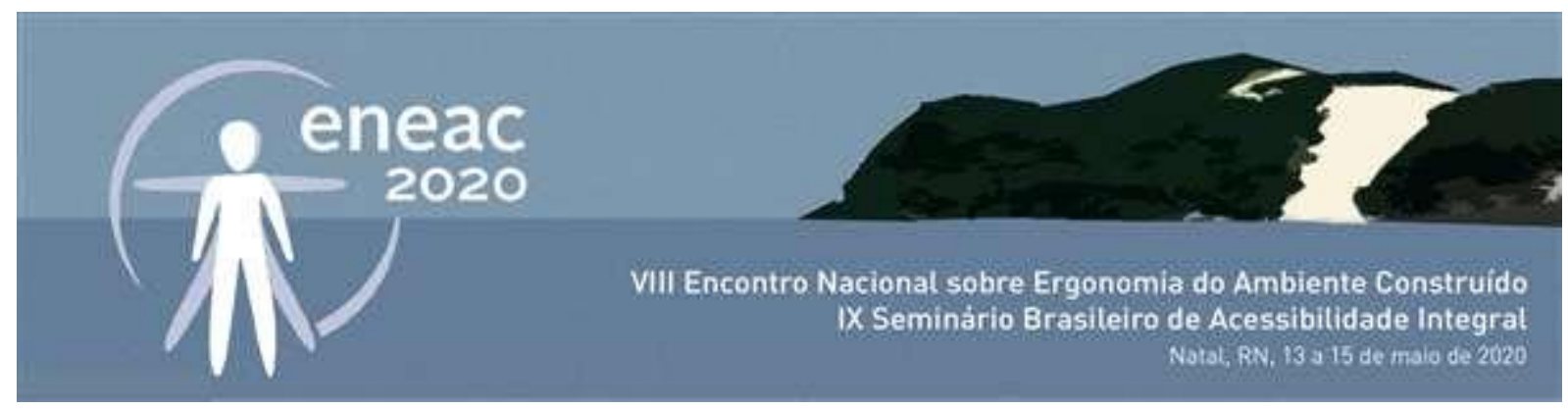

\section{ABSTRACT}

This article aims to present the study conducted in a public school of the municipal school system of the city of Fortaleza-CE, from the application of Ergonomic Methodology for the Built Environment MEAC, proposed by Villarouco (2008). The steps followed for the study were: Global Environmental Analysis, Identification of the Environmental Configuration, Evaluation of the Environment in Use, Environmental Perception of the User and Ergonomic Diagnosis of the Environment. In this last stage a diagnosis was elaborated highlighting some problems found and relating recommendations for the adaptation of the space to its users, in order to propose improvements applicable to the environments. The results obtained after the analysis point to the need for improvements in some aspects, especially related to comfort and accessibility. Finally, the crucial points are the interactions between the variables of the built environment and the users' activities, in order to achieve the ideals defined by the Ergonomics studies.

KEYWORDS: ergonomic; school; MEAC; user perception.

\section{INTRODUÇÃO}

Esse estudo versa sobre ergonomia de ambiente escolar, voltando-se à análise ergonômica de uma escola municipal de Fortaleza, Ceará. Na sociedade atual, a escola faz parte da vida dos indivíduos desde a mais tenra infância e por um longo intervalo de tempo. Dessa forma, é uma instituição social de extrema importância para o processo de desenvolvimento cognitivo, físico, afetivo e social dos alunos. Como um espaço de interações e de aquisição de conhecimentos, o ambiente escolar exerce influência significativa sobre os indivíduos, podendo favorecer ou não os processos de ensino e aprendizagem aos quais se dedica.

No que tange a esses processos, a sala de aula assume papel de destaque, representando o posto de trabalho de professores e alunos, no qual esses permanecem a maior parte do tempo em que estão na instituição. Nesse trabalho propomos a avaliação ergonômica de uma escola situada no bairro da Aldeota, em Fortaleza, de forma a identificar as potencialidades e limites do ambiente construído na sua relação com seus usuários e com as atividades que ali se realizam, buscando contribuir para o bom funcionamento dessa instituição de ensino. Por fim, o presente trabalho irá ser disponibilizado para a respectiva instituição de ensino e serão destinados esforços a fim de viabilizar verbas para implantação das recomendações.

\section{METODOLOGIA}

A presente pesquisa tem caráter exploratório e utiliza a Metodologia Ergonômica para o Ambiente Construído - MEAC, conforme proposta por Villarouco (2008). Trata-se de uma abordagem voltada à análise e compreensão do sistema ambiente-homem-atividade, a qual envolve cinco etapas, que passamos a apresentar.

Etapa 1 - Análise Global do Ambiente: fase de reconhecimento, com abordagem macro, através da qual se busca uma visão sistêmica do ambiente a partir de levantamentos referentes a materiais, pessoal, equipamentos, fluxos, entre outros itens. Envolve o uso de observação assistemática, Walkthrough, registro fotográfico, entrevista e outras técnicas para o início da identificação das principais atividades realizadas na instituição - o que se faz e como se faz; 


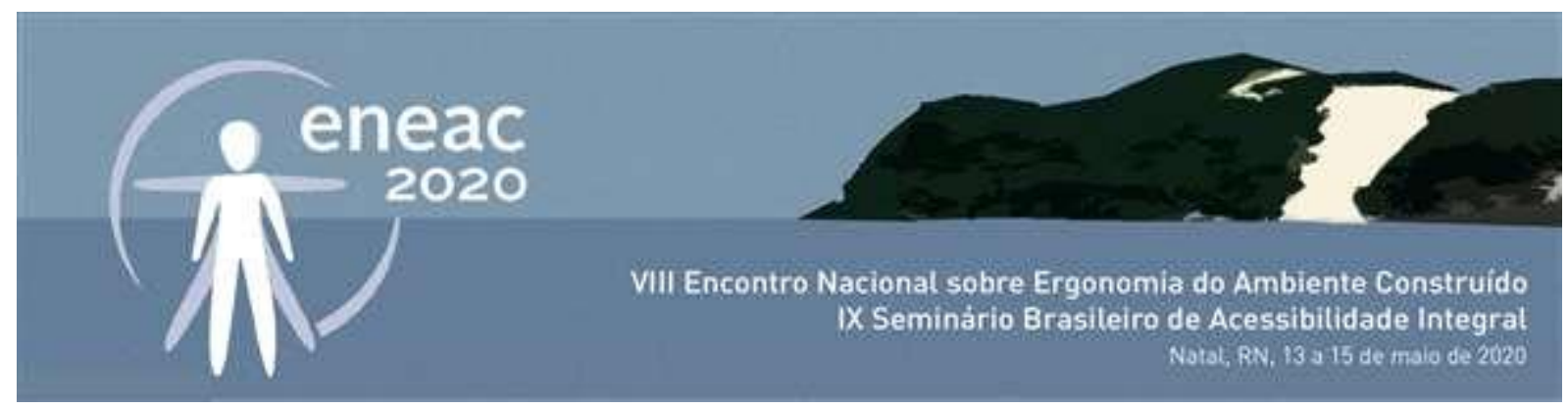

Etapa 2 - Identificação da Configuração Ambiental: Busca o conhecimento do trabalho realizado, das tarefas desempenhadas, dos postos e estações de trabalho, equipamentos e tecnologias utilizadas. Envolve o levantamento de dados de dimensionamento, iluminação, ventilação, ruído, fluxos, layout, deslocamentos, postos de trabalho, materiais de revestimento e condições de acessibilidade e de segurança, os quais servem a elaboração das primeiras hipóteses sobre como o ambiente influencia a realização de atividades de trabalho. Inclui entrevistas com os usuários dos espaços, elaboração de plantas e fluxogramas, observação sistemática e realização de medições de temperatura, iluminamento, entre outros itens.

Etapa 3 - Avaliação do Ambiente em Uso: fase de análise efetiva da realização das atividades, visando verificar o quanto o ambiente facilita ou dificulta as mesmas. Envolve observações cuidadosas da execução das tarefas com uso de fotografias, filmagens, entrevistas, questionários e outros. Uso da antropometria para análise dos postos de trabalho, mobiliários e equipamentos.

Etapa 4 - Percepção Ambiental do Usuário: nessa fase se busca identificar como o usuário percebe o ambiente, com uso de ferramentas tais como Mapas Mentais e Cognitivos, Constelação de Atributos, Técnica de Mapeamento Visual, Modelo de Análise Hierárquica, Método de Análise Visual, Walktrough, Observação Incorporada, Poema dos Desejos, Seleção Visual, dentre tantos existentes. O Poema dos Desejos, que utilizamos na nossa pesquisa, é um instrumento desenvolvido por Henry Sanoff. Através do qual os usuários de determinado lugar expressam suas necessidades, sentimentos e desejos referentes ao ambiente analisado com base em um conjunto de sentenças do tipo Eu gostaria que o [edifício|ambiente].... Trata-se de um instrumento não estruturado e de livre expressão que se baseia na espontaneidade da resposta (MACHADO; AZEVEDO; ABDALLA, 2011);

Etapa 5 - Diagnóstico Ergonômico do Ambiente: O diagnóstico envolve a apresentação de todas as informações necessárias à compreensão do sistema ambiente-homem-atividade, apontando-se problemas e pontos fortes e sugestões de melhorias e soluções.

\section{RESULTADOS E DISCUSSÕES}

\subsection{Análise Global do Ambiente}

O estudo foi realizado em uma escola municipal, localizada no bairro Meireles, na cidade de Fortaleza/CE. A edificação térrea, com aproximadamente $1276,28 \mathrm{~m}^{2}$, sendo seu horário de funcionamento de segunda a sexta, das 7 às $11 \mathrm{~h}$ (manhã), 13 às $17 \mathrm{~h}$ (tarde) e 19 às $21 \mathrm{~h}$ (noite). Em outros horários acontecem atividades extracurriculares (capoeira, aula de música e recreação infantil), além de servir à comunidade como espaço de confraternização em eventos variados como formaturas e casamentos.

O quadro de funcionários é composto por 36 pessoas e as funções exercidas na instituição estão distribuídas por áreas: professores(as), auxiliares de limpeza, serviços gerais, administrativos e apoio. Sobre os alunos, totalizam-se 330, sendo 118 pela manhã, 118 a tarde e 94 à noite. Nos turnos da

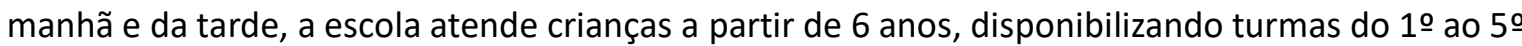
ano do ensino fundamental; enquanto à noite, o ensino é direcionado aos adultos pelo programa Ensino de Jovens e Adultos (EJA). 


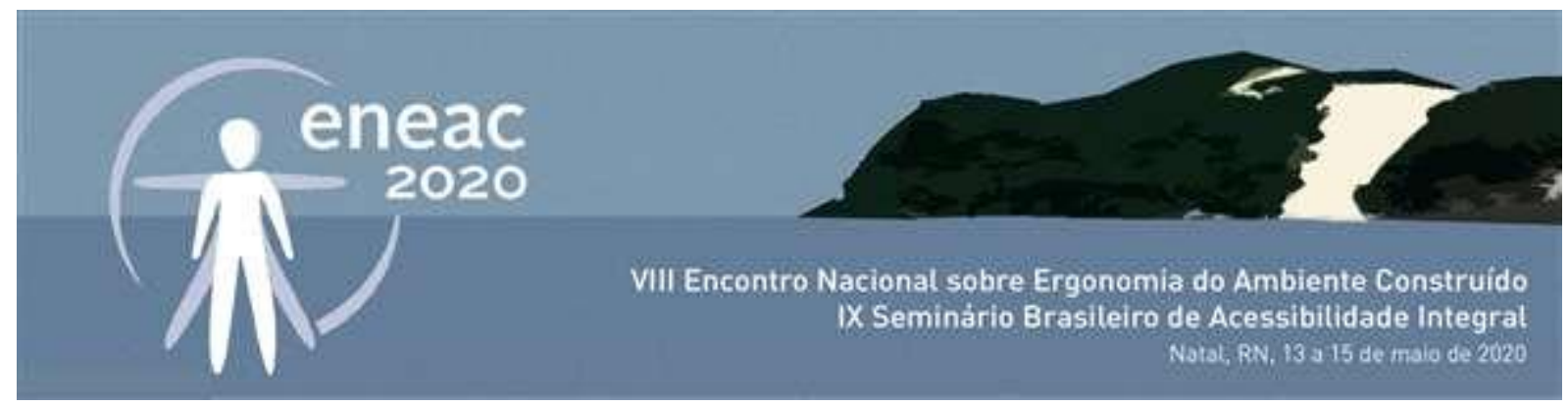

Os ambientes são distribuídos no espaço da escola (Figura 01) da seguinte forma: 01 - Secretaria; 02 Diretoria; 03 - Depósito; 04 - Sala do 5o ano; 05 - Sala multiuso; 06 - Sala do 2o ano; 07 - WC Masculino; 08 - WC Feminino; 09 - Sala do 10 ano; 10 - Sala do 3 ano; 11 - Sala do 40 ano; 12 Vestiário Funcionários/Reforço; 13 - Refeitório; 14 - Cozinha; 15 - Área de playground; 16 - Área de pátio; 17 - Quadra.

Figura 01. Planta baixa da escola com ambientes analisados em destaque na cor azul.

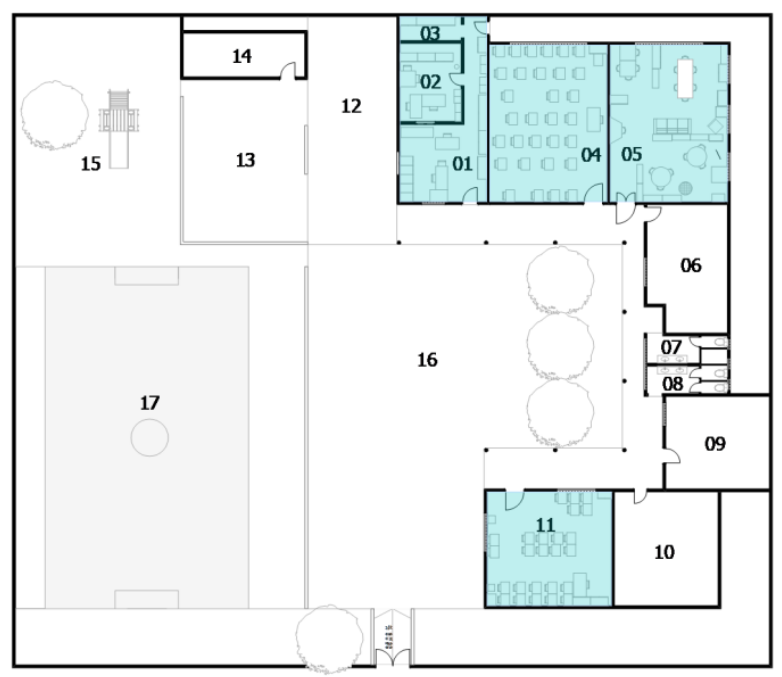

Fonte: Arquivo pesquisa.

\subsubsection{Descrição do ambiente}

Esta primeira etapa foi realizada nos dias 16 e 17 de outubro, sendo as informações coletadas através de observações e conversas com funcionários, utilizando como ferramenta de percepção o Walkthrough.

Como primeira impressão, as sensações sentidas pelos integrantes do grupo foram: espaço menor do que o necessário para contemplar todo o programa de necessidades; banheiros com má infraestrutura; pisos irregulares; playground pouco atrativo. Em contrapartida, notou-se ser um lugar limpo, organizado e com pátio arejado e sombreado graças às 3 frondosas árvores do tipo castanhola presentes no local. Sobre as salas de aula, observou-se a presença de poucos espaços para armazenamento de materiais didáticos e surgiu a preocupação quanto aos mobiliários (cadeiras e mesas), tendo em vista que o mesmo mobiliário é utilizado nos três turnos, não sendo compatíveis com os adultos que ocupam o mesmo ambiente no período noturno. A quadra não possui alambrado de proteção, nem é coberta. É sombreada parcialmente por uma árvore que fica ao lado dela.

É importante destacar que a instituição ocupa o espaço de uma antiga residência unifamiliar, tendo sido o prédio doado para a prefeitura e passado por poucas adaptações físicas, o que explica a incompatibilidade da estrutura com o uso em alguns aspectos. 


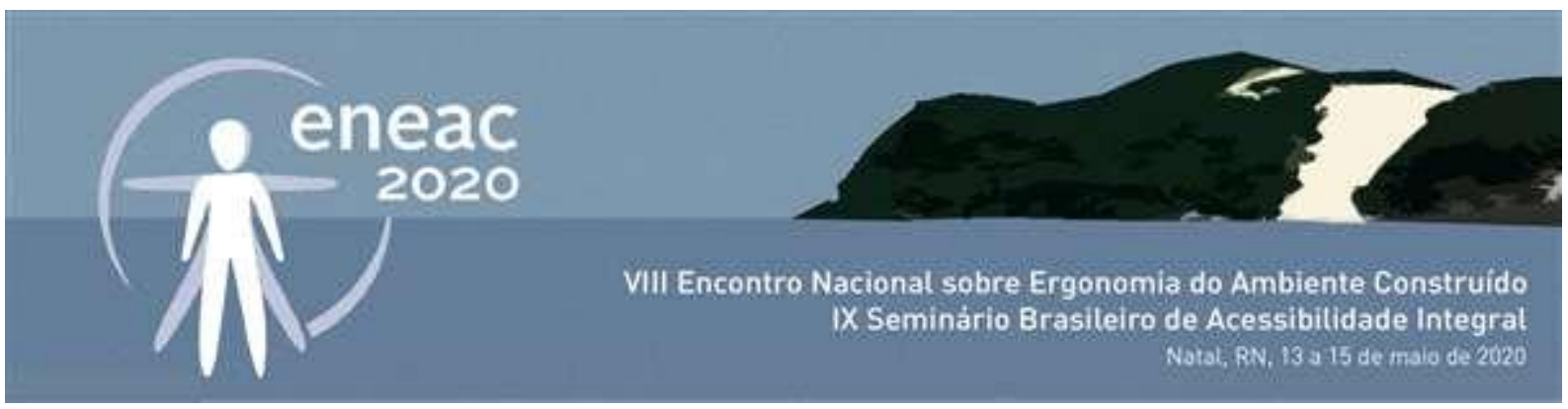

\subsubsection{Iluminação e ventilação}

Todas as salas de aula possuem elementos vazados do tipo cobogó como elementos de vedação no lugar de esquadrias, graças ao projeto original da casa. Entretanto, essa estrutura apesar de apresentar vantagens para circulação de ventilação e iluminação natural, possibilita a entrada de ruídos indesejados para o ambiente de ensino. Desta forma, os vãos de esquadria receberam plástico ou policarbonato para viabilizar a climatização artificial através de aparelhos de ar-condicionado. Em algumas salas, a climatização continua sendo feita por meio de ventiladores. No período da noite, foi possível perceber e avaliar que em todos os ambientes, a iluminação existente é insuficiente para o bom desempenho das atividades propostas.

\subsubsection{Materiais}

Os principais materiais identificados foram: piso em concreto no pátio e tipos de cerâmica variados nas áreas de circulação e nos ambientes internos, além de faixas de areia nos recuos do terreno; teto com forro de PVC nas salas de aula, sala multiuso e diretoria; telha cerâmica aparente na secretaria, nos banheiros, no refeitório, na cozinha e no reforço. As paredes das salas de aula, sala multiuso e corredores apresentam revestimento em tijolinho com 1,50m de altura e restante da parede e demais ambientes com pintura em tons de amarelo; mobiliário predominantemente em plástico e madeira (carteiras e mesas) e aço (armários e estantes).

\subsubsection{Acessibilidade}

Foram encontrados diversos problemas de acessibilidade na escola. Iniciando pela entrada que se resume a um único acesso para entrada e saída - fluxo de alunos, pais e funcionários, com uma rampa de inclinação de 35\%, sem guarda-corpo nem corrimão. Há também desníveis nos locais de transição de ambientes, como por exemplo, do pátio para a circulação das salas, como também para a quadra e para o playground.

No refeitório o mobiliário tem dimensões exclusivas para crianças pequenas e o balcão tem altura fora do recomendado pela NBR 9050:2015, medindo 1,07m de altura, quando o ideal seria $85 \mathrm{~cm}$ com superfície para aproximação horizontal. Além disso, a escola não possui banheiro acessível e nenhum tipo de sinalização tátil para deficientes visuais.

Quanto à quadra identifica-se que não possui alambrado de proteção, nem espaço para cadeirante onde ele possa assistir as atividades ali desenvolvidas de forma segura.

\subsection{Avaliação da configuração ambiental}

Por tratar-se de um extenso programa, foram selecionados alguns ambientes para aplicação das ferramentas de análise, sendo eles: sala multiuso, salas de aula do $4 \stackrel{\circ}{\circ}$ e anos diurnos e EJA II e III, no turno da noite, sala da diretoria e secretaria (Figura 1). A escolha destes ambientes teve como critério a dinamicidade das atividades que ocorrem no local, como no caso da sala multiuso, diretoria e secretaria. As salas de aulas foram selecionadas com base na idade e maturidade escolar das crianças, levando em consideração que em uma fase posterior da MEAC seria aplicada uma ferramenta de percepção com os usuários. 


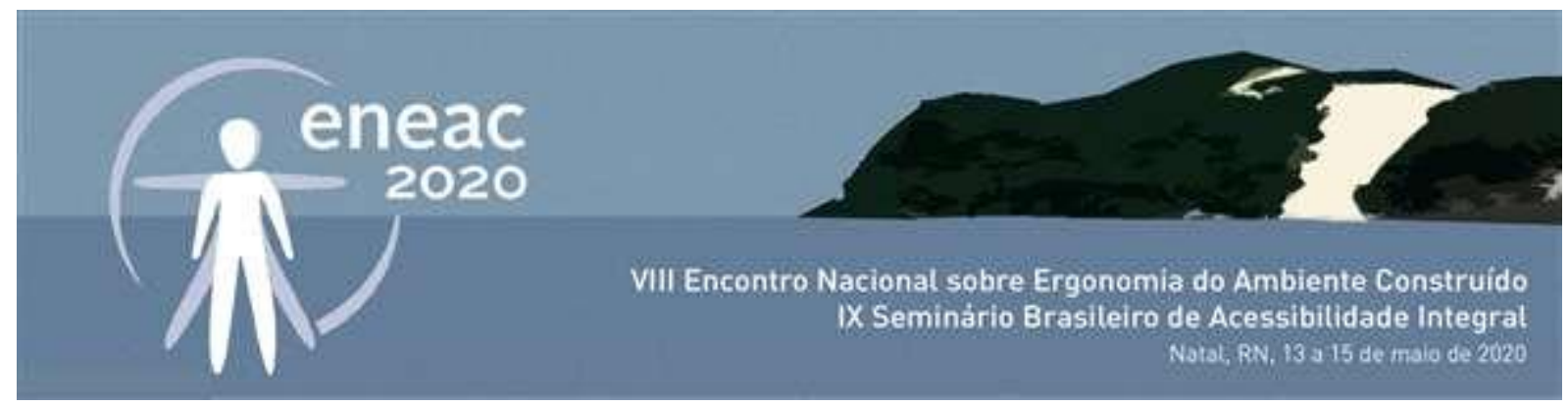

\subsubsection{Layout e mobiliário}

O mobiliário existente na sala do 4ำ ano (Figura 2) é composto por 3 armários de aço, quadro branco, 26 conjuntos de mesas e cadeiras para os alunos, sendo 19 conjuntos na cor vermelha (Figura 3) que são indicadas, segundo o fabricante, para alunos com estatura de 1,33m a 1,59m, e 7 conjuntos na cor azul, indicadas para alunos com estatura de $1,59 \mathrm{~m}$ a $1,88 \mathrm{~m}$ ), e conjunto de mesa e cadeira para o professor.

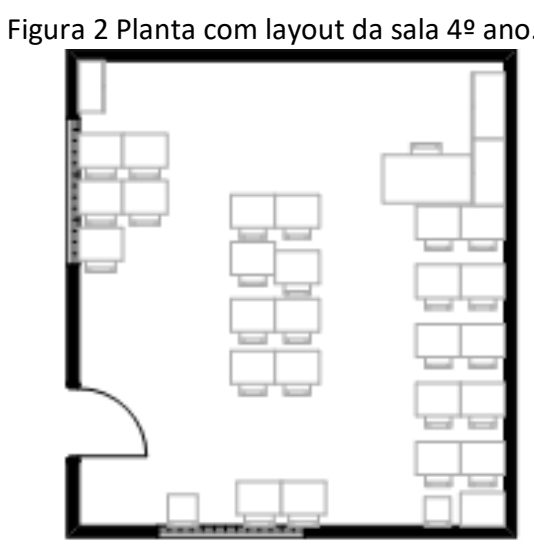

Fonte: Arquivo pesquisa.

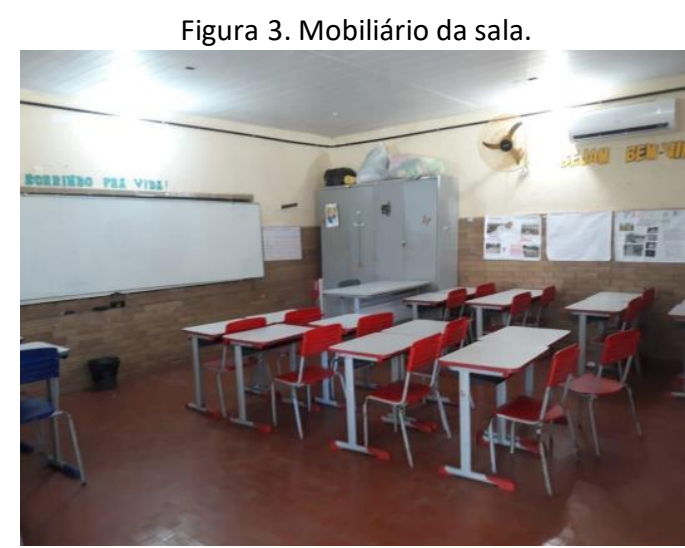

Fonte: Arquivo pesquisa.

Na sala do 50 ano o mobiliário (Figura 4) existente na sala é formado por armário em aço, quadro branco, 32 conjuntos de mesas e cadeiras para os alunos (na cor azul, indicadas segundo o fabricante para alunos com estatura de 1,59 a 1,88 m), e conjunto de mesa e cadeira para o professor (Figura 5).

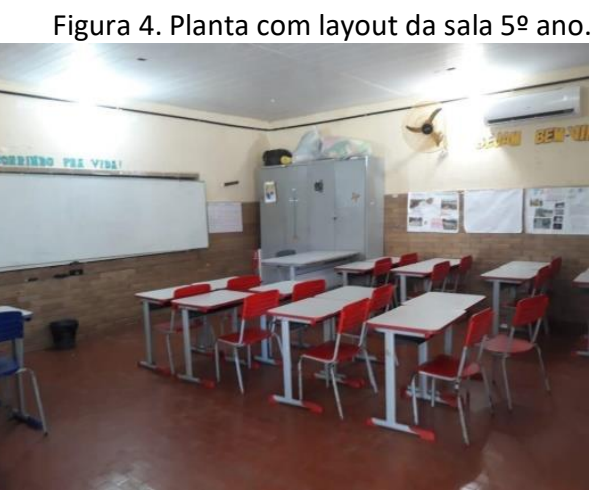

Fonte: Arquivo pesquisa.
Figura 5. Mobiliário da sala 5o ano.

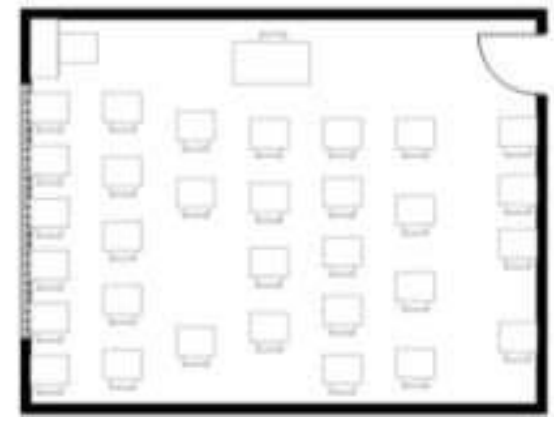

Fonte: Arquivo pesquisa.

A sala multiuso (Figura 6) abriga algumas funções que subdivide o ambiente em três espaços: biblioteca, sala de professores e sala de reforço. Esses espaços são delimitados pelo próprio mobiliário (Figura 7). Devido à sala abrigar múltiplas funções existem muitos mobiliários no espaço, que são: 9 estantes com livros, 6 armários em aço, 7 mesas, 17 cadeiras, sofá, puff, refrigerador, bebedouro, ventilador, além de caixas organizadoras e nichos. 


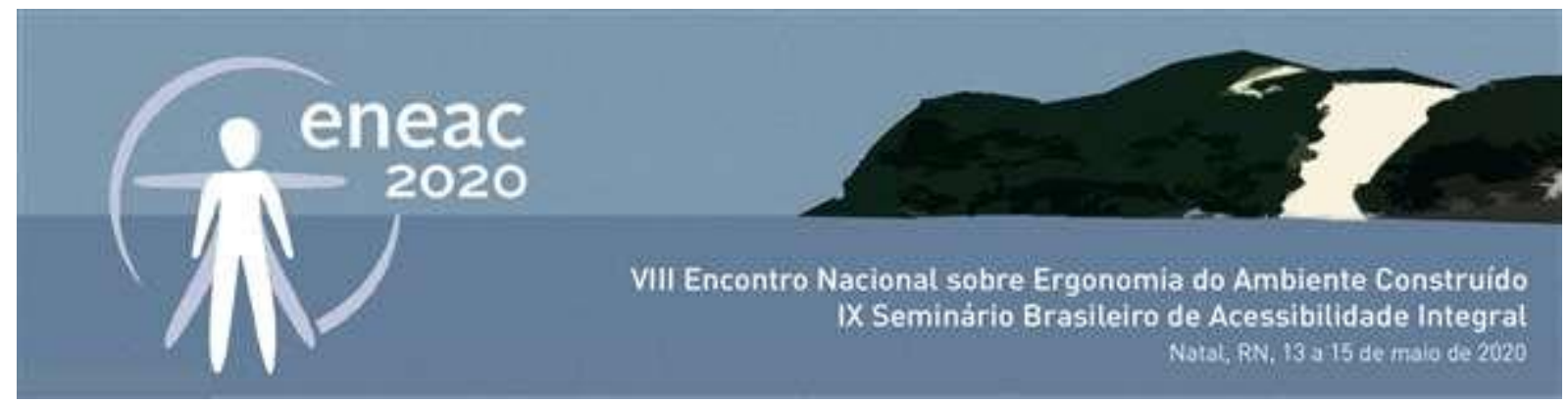

Figura 6. Planta com layout da sala multiuso.

Figura 7. Ambiente da sala dos professores

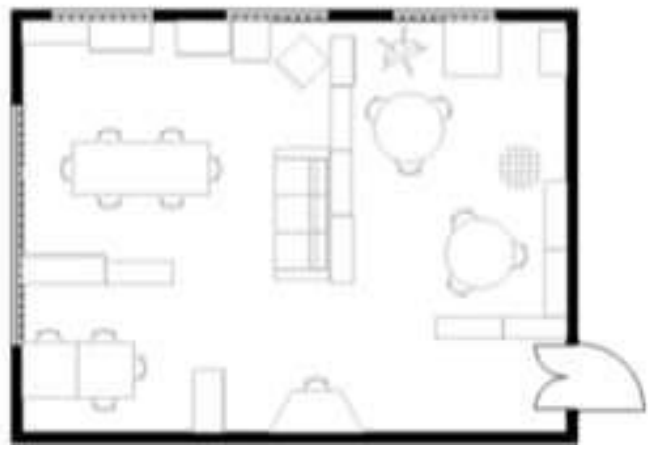

Fonte: Arquivo pesquisa.

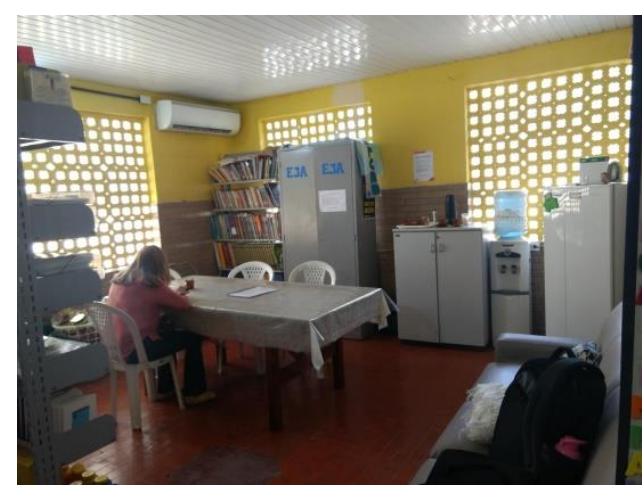

Fonte: Arquivo pesquisa.

O espaço da secretaria antecede o da diretoria, ambos interligados por um corredor que leva também a um depósito (Figura 8). No primeiro ambiente (Figura 9), o layout é composto por 4 mesas de madeira (sendo que duas delas são usadas apenas como suporte de materiais), 3 cadeiras reguláveis, 5 arquivos de aço, além de 8 armários e estantes de aço que estão dispostos ao longo de parte da secretaria até o final do corredor (Figura 10).

Figura 8. Planta com layout secretaria/diretoria.

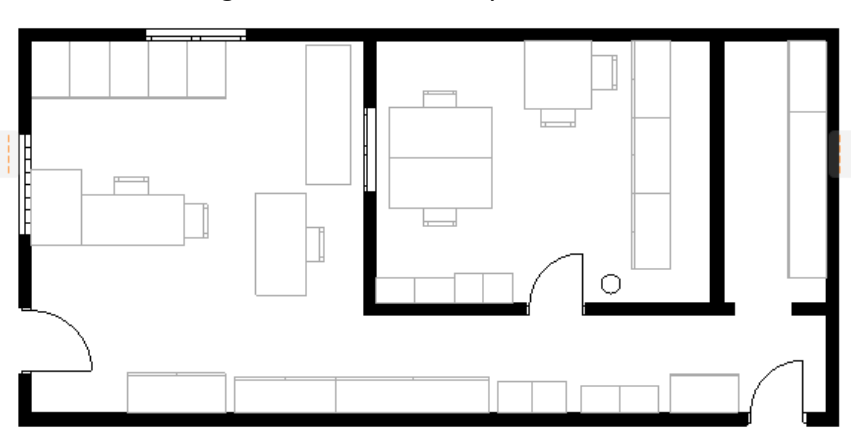

Fonte: Arquivo pesquisa.

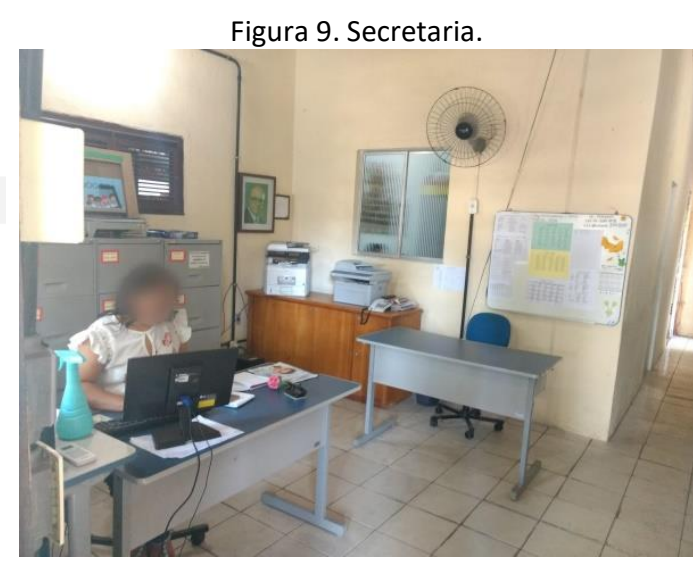

Fonte: Arquivo pesquisa.

Na diretoria (Figura 11) existem 3 mesas, sendo uma de plástico (que serve de apoio para refeições) e as outras são de madeira com gaveteiro, 4 cadeiras de aço (sendo 2 reguláveis) com assento acolchoado, 4 armários e 2 estantes de aço e um gelágua, além de algumas caixas que estão alocadas atrás dos armários. O depósito que fica após a sala da diretoria, é um espaço pouco visitado e lá se encontra além de algumas caixas espalhadas pelo chão, um armário e uma estante. 


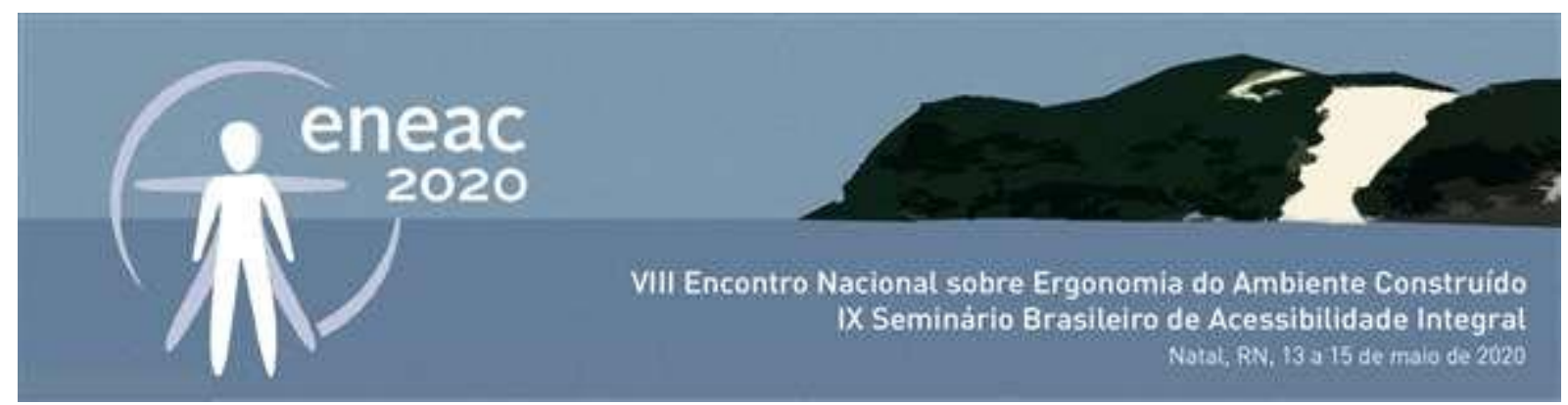

Figura 10. Corredor.
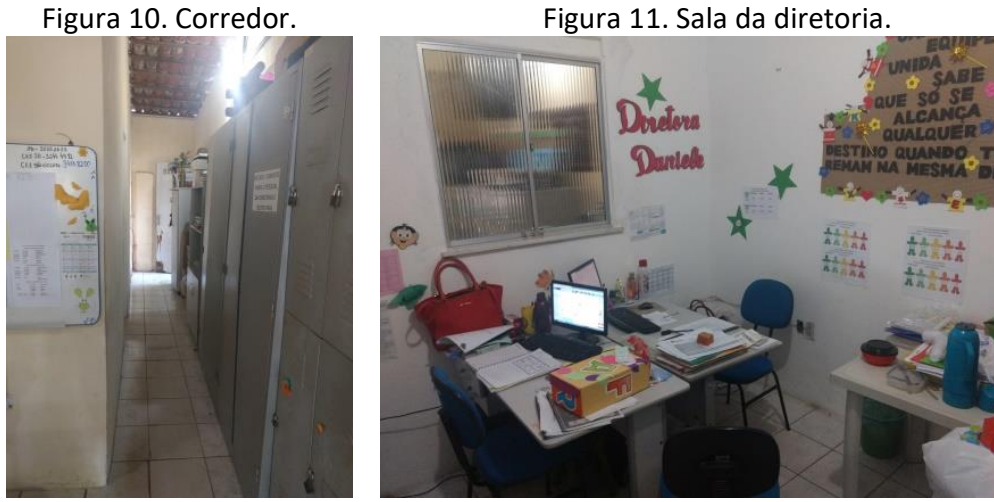

Fonte: Arquivo pesquisa.

Fonte: Arquivo pesquisa.

\subsubsection{Acessibilidade e Desenho Universal}

A NBR 9050:2015 foi a norma técnica utilizada para avaliação dos parâmetros de acessibilidade dos espaços. Para além dos aspectos já mencionados anteriormente sobre este quesito nos demais espaços da escola, nos ambientes selecionados foram verificados também: vão das portas, tipo de maçaneta, presença de desníveis no acesso, comunicação visual, comunicação em Braille, contraste entre piso e parede e nas salas de aula foi verificado também a altura do quadro.

Com exceção da porta da diretoria, todas as outras analisadas possuem vão adequado (acima de 80 $\mathrm{cm}$ ). A porta da sala multiuso possui duas folhas medindo $50 \mathrm{~cm}$ cada uma, além de uma grade de ferro que impossibilita a sua abertura por uma pessoa sem mobilidade nas mãos. Em relação às maçanetas foram encontradas apenas do tipo bola ou ferrolhos, enquanto que o recomendado pela norma é de alavanca. Apenas a sala da diretoria não possui contraste entre piso e parede.

A sala da secretaria é a única que possui desnível para seu acesso. A comunicação visual das salas geralmente encontra-se ou colada na porta ou acima desta (com mais de 2,10 m de altura), estando em desconformidade com a NBR 9050/2015, que diz que a comunicação visual deve estar a na faixa de altura entre 1,20 m e 1,60 m e deve ser fixada ao lado da porta e acompanhada da sinalização em Braille (que não foi encontrada em nenhuma sala). Os quadros nas salas de aula estão com altura correta a $90 \mathrm{~cm}$ do chão.

\subsubsection{Avaliação do conforto lumínico}

Para avaliação do conforto lumínico foi utilizado o aparelho luxímetro na superfície onde são realizadas as atividades de cada ambiente. As medições ocorreram em três horários distintos: manhã, tarde e noite. É importante ressaltar que durante a noite, a diretoria não funciona, portanto os dados foram coletados apenas nos outros dois períodos. Os resultados obtidos foram comparados à NHO 11 de 2018. Ao observar que a iluminação não era uniforme em nenhum dos ambientes (existem diversas lâmpadas fluorescentes espalhadas pelos cantos das salas), optou-se por fazer verificar em mais de um ponto para melhor analisar essa variação. A localização dos pontos pode ser verificada nas Figuras 12,13,14 e 15, e os valores obtidos na Tabela 1. 


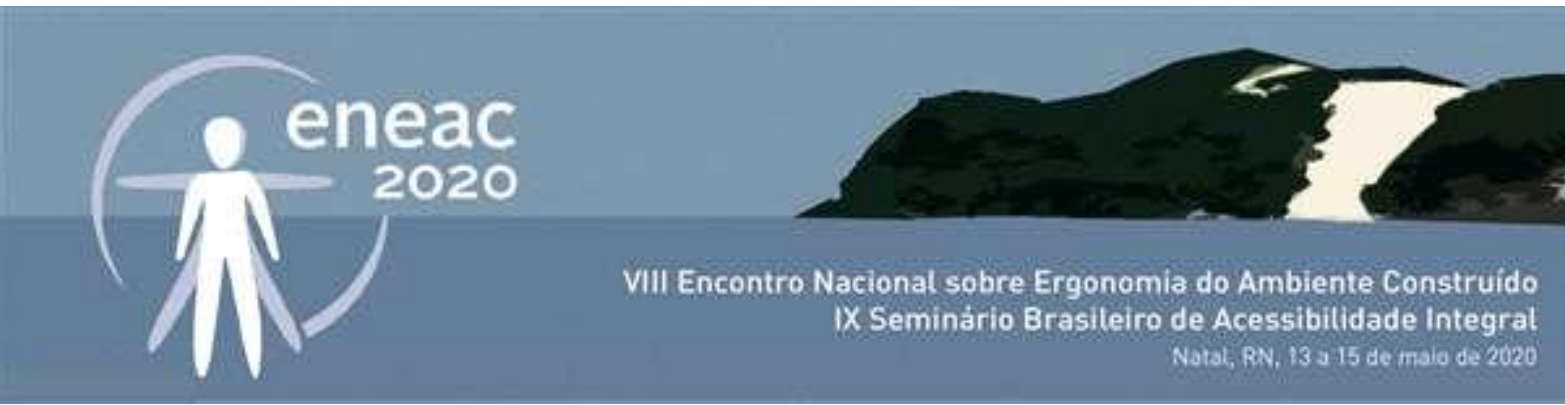

Figura 12. Sala 50 ano.

Figura 13. Sala multiuso.

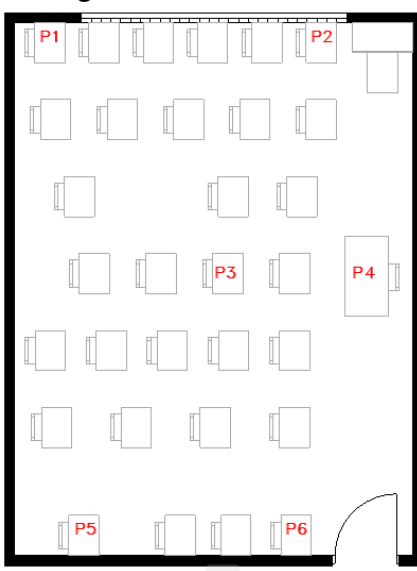

Fonte: Arquivo pesquisa.

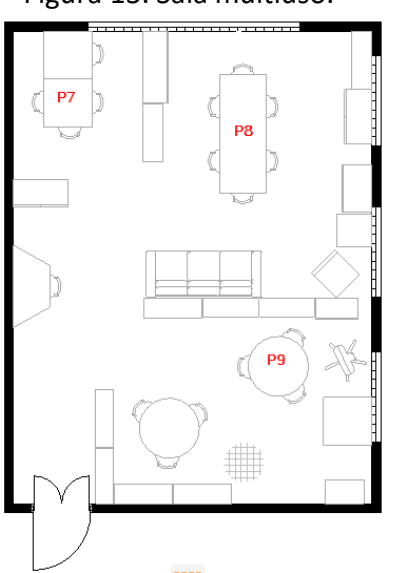

Fonte: Arquivo pesquisa.
Figura 14. Sala 4o ano.

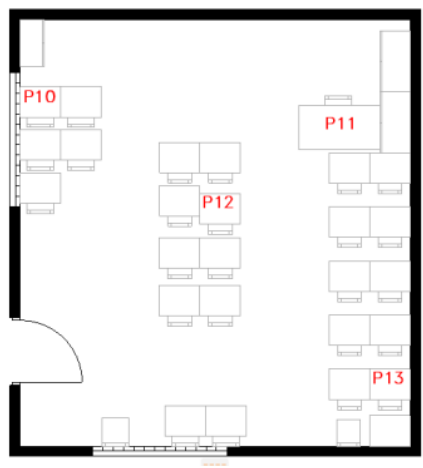

Fonte: Arquivo pesquisa.
Figura 15. Secretaria/Diretoria.

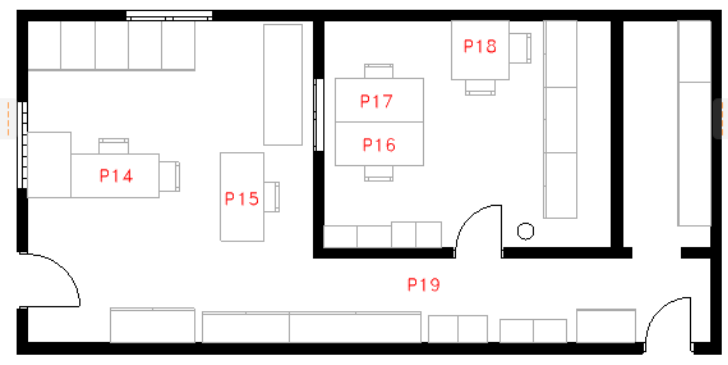

Fonte: Arquivo pesquisa

Tabela 1 - Níveis de luminância

\begin{tabular}{|c|c|c|c|c|c|}
\hline Ponto & Ambiente & $\begin{array}{c}\text { Medição- } \\
\text { 10:00h } \\
\text { (lux) }\end{array}$ & $\begin{array}{c}\text { Medição- } \\
\text { 14:00h } \\
\text { (lux) }\end{array}$ & $\begin{array}{c}\text { Medição- } \\
\text { 20:00h } \\
\text { (lux) }\end{array}$ & $\begin{array}{c}\text { NHO } 11 \\
\text { (lux) }\end{array}$ \\
\hline $\mathrm{P} 1$ & Sala de aula $5^{\circ}$ ano & 48 & 42 & 40 & 300 \\
\hline $\mathrm{P} 2$ & Sala de aula $5^{\circ}$ ano & 94 & 142 & 95 & 300 \\
\hline P3 & Sala de aula $5^{\circ}$ ano & 42 & 48 & 47 & 300 \\
\hline $\mathrm{P} 4$ & Sala de aula $5^{\circ}$ ano & 63 & 65 & 76 & 300 \\
\hline $\mathrm{P} 5$ & Sala de aula $5^{\circ}$ ano & 39 & 44 & 55 & 300 \\
\hline P6 & Sala de aula $5^{\circ}$ ano & 129 & 134 & 108 & 300 \\
\hline $\mathrm{P7}$ & Sala multiuso(reforço) & 133 & 142 & 49,7 & 300 \\
\hline P8 & Sala multiuso (sala de professores) & 104 & 270 & 39 & 300 \\
\hline P9 & Sala multiuso (biblioteca) & 57 & 119 & 42 & 500 \\
\hline P10 & Sala de aula $4^{\circ}$ ano & 98,3 & 115 & 90 & 300 \\
\hline $\mathrm{P} 11$ & Sala de aula $4^{\circ}$ ano & 90,7 & 124 & 87 & 300 \\
\hline $\mathrm{P} 12$ & Sala de aula $4^{\circ}$ ano & 95 & 139 & 67 & 300 \\
\hline $\mathrm{P} 13$ & Sala de aula $4^{\circ}$ ano & 42 & 67 & 52,8 & 300 \\
\hline
\end{tabular}




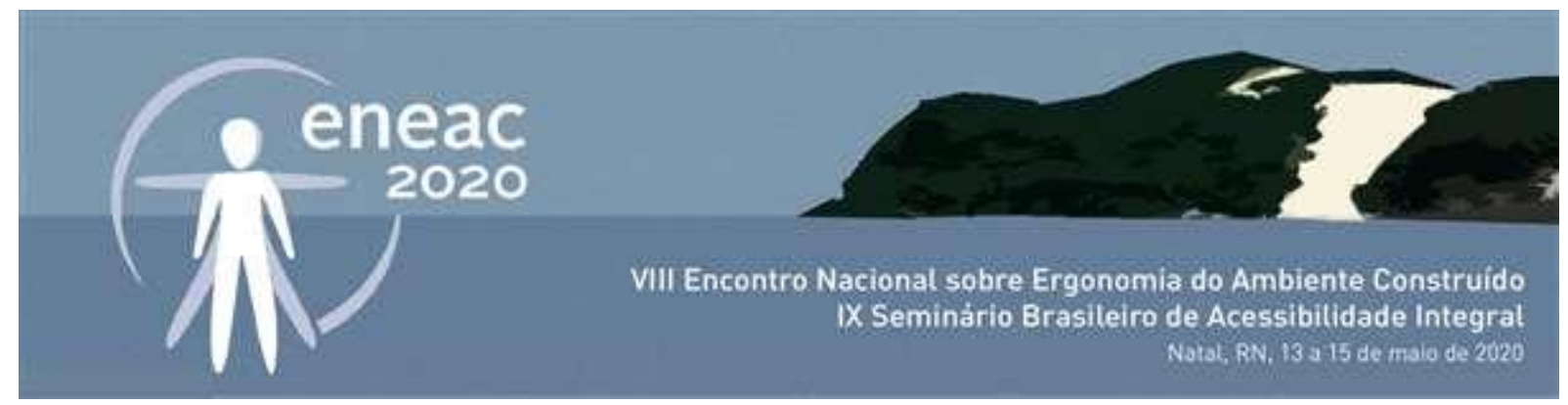

\begin{tabular}{c|c|c|c|c|c} 
P14 & Secretaria & 148 & 116 & 57 & 500 \\
\hline P15 & Secretaria & 75 & 62 & 31 & 500 \\
\hline P16 & Diretoria & 73 & 76 & - & 500 \\
\hline P17 & Diretoria & 61 & 64 & - & 500 \\
\hline P18 & Diretoria & 81 & 77 & - & 500 \\
\hline P19 & Circulação & 51 & 48 & 35 & 100 \\
\hline
\end{tabular}

Fonte: elaborada pelos autores.

Nenhum dos valores levantados correspondem aos níveis mínimos de iluminância descritos na NHO 11. Sabe-se que a iluminação artificial é a principal fonte de iluminação desses ambientes. Houve uma determinada variação dos valores em decorrência do horário de realização da medição. Isso pode ser explicado pela influência (mesmo não sendo tão intensa) da iluminação natural.

\subsubsection{Avaliação do Conforto Acústico}

Para avaliação do conforto acústico dos ambientes, teve-se como parâmetro os intervalos para o nível de ruído ambiente indicados pela ABNT NBR 10.152/2000. Foram analisadas as medições do ruído interno utilizando o aplicativo Sound Meter. A tabela 2 apresenta os resultados levantados:

Tabela 2 - Níveis de ruído.

\begin{tabular}{|c|c|c|c|c|}
\hline Ambiente & $\begin{array}{c}\text { Horário } \\
\text { 10:00h } \\
\text { (dB) }\end{array}$ & $\begin{array}{c}\text { Horário } \\
\text { 15:00h } \\
\text { (dB) }\end{array}$ & $\begin{array}{c}\text { Horário } \\
\text { 20:00h } \\
\text { (dB) }\end{array}$ & $\begin{array}{l}\text { NBR } 10152 \\
\text { (dB) }\end{array}$ \\
\hline Sala de aula $4^{\circ}$ ano & 54 & 49.5 & 85 & $35-45$ \\
\hline Sala de aula $5^{\circ}$ ano & 59.5 & 54 & 74 & $35-45$ \\
\hline Sala multiuso & 57.5 & 42.8 & 75 & $35-45$ \\
\hline Secretaria & 51 & 40 & 72 & $35-45$ \\
\hline Diretoria & 53 & 39 & - & $35-45$ \\
\hline
\end{tabular}

Fonte: elaborada pelos autores.

Comparando os valores medidos nos ambientes com os níveis indicados pela norma, verifica-se que a maioria as medições apresentam índices de decibéis superiores aos desejáveis, as únicas exceções foram nas salas multiuso, secretaria e diretoria. Os valores mais altos foram os obtidos no turno da noite.

\subsubsection{Avaliação do Conforto Térmico}

A avaliação do conforto térmico foi realizada através da medição de temperatura interna dos ambientes nos três turnos distintos (manhã, tarde e noite). $O$ equipamento utilizado foi um termômetro de globo e o os dados levantados foram comparados com os parâmetros descritos na NR 17. A tabela 3 apresenta os valores em graus Celsius. 


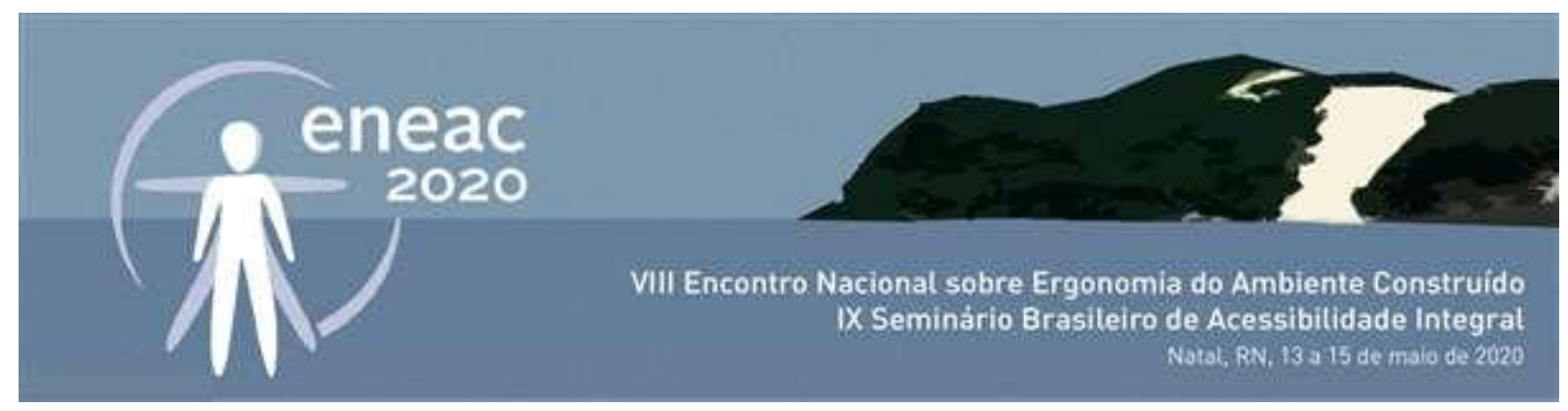

Tabela 3 - Níveis de temperatura

\begin{tabular}{|c|c|c|c|c|}
\hline Ambiente & $\begin{array}{l}\text { Medição-10:00h } \\
\text { (oC) }\end{array}$ & $\begin{array}{l}\text { Medição-15:00h } \\
\text { (oC) } \\
\end{array}$ & $\begin{array}{l}\text { Medição-20:00h } \\
\text { (oC) }\end{array}$ & $\begin{array}{c}\text { NR } 17 \\
\text { (oC) }\end{array}$ \\
\hline Sala de aula $4^{\circ}$ ano & 26.4 & 28.9 & 26.6 & $20-23$ \\
\hline Sala de aula $5^{\circ}$ ano & 26.7 & 25.8 & 25.8 & $20-23$ \\
\hline Sala multiuso & 26.5 & 30.5 & 26.9 & $20-23$ \\
\hline Secretaria & 27 & 30 & 26.7 & $20-23$ \\
\hline Diretoria & 24.1 & 31.7 & - & $20-23$ \\
\hline
\end{tabular}

Fonte: elaborada pelos autores.

Dos ambientes analisados, a secretaria é a única sala que não possui climatização artificial através de aparelhos de ar condicionado. Mesmo assim, todos os níveis de temperatura ficaram acima da média estipulada pela NR 17. Constata-se que o período da tarde foi o de pior desempenho.

\subsection{Avaliação do ambiente em uso}

A avaliação do ambiente em uso ocorreu mediante a observação dos usuários realizando as atividades nos espaços selecionados: sala de 40 e 5o séries; sala multiuso; sala de diretoria/secretaria. Foram analisados, dentre outros aspectos, os principais fluxos e deslocamentos dos usuários, sendo utilizados modelos antropométricos para verificar o dimensionamento do layout existente. Os modelos antropométricos sugeridas por Panero \& Zelnik (2008) são baseados nas medidas humanas adultas masculinas, e possuem cores diferentes dependendo do nível de adequação encontrada na circulação. O manequim na cor verde significa circulação adequada, na cor amarela indica situação de atenção ou risco e na cor vermelha significa situação inadequada. Quando utilizado na cor cinza, representa o usuário na situação de indivíduo parado, no entanto, este manequim não foi utilizado nos ambientes com predominância de usuários infantis, visto ser um modelo baseado nas medidas de um indivíduo adulto e não se adequar aos mobiliários do espaço. As figuras 16, 17,18 e 19 apresentam as plantas baixas com as representações desses modelos antropométricos: 


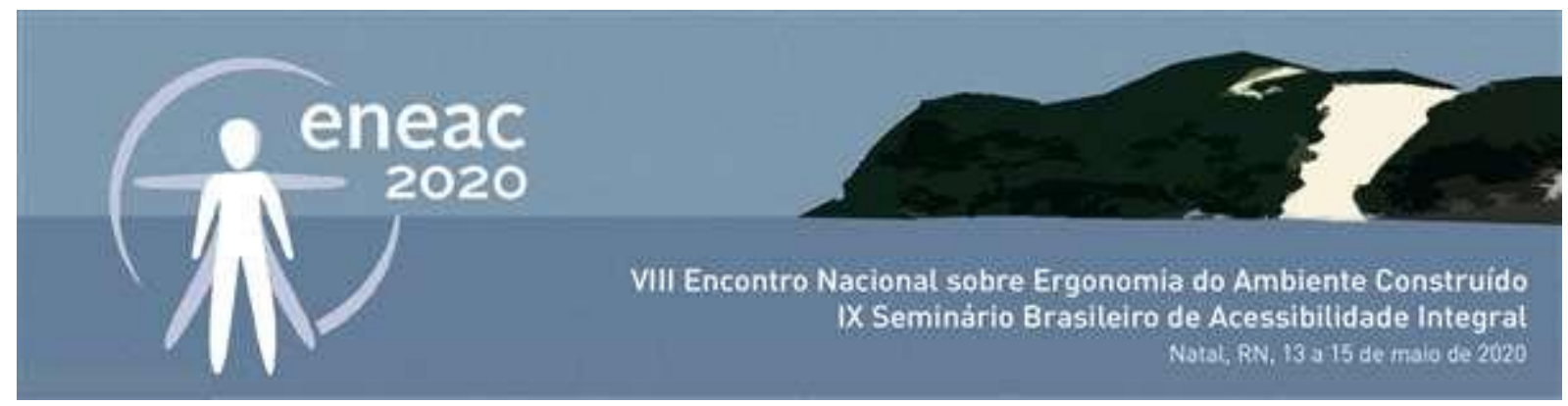

Figura 16. Sala do 4ㅇa ano

Figura 17. Sala do 5o ano
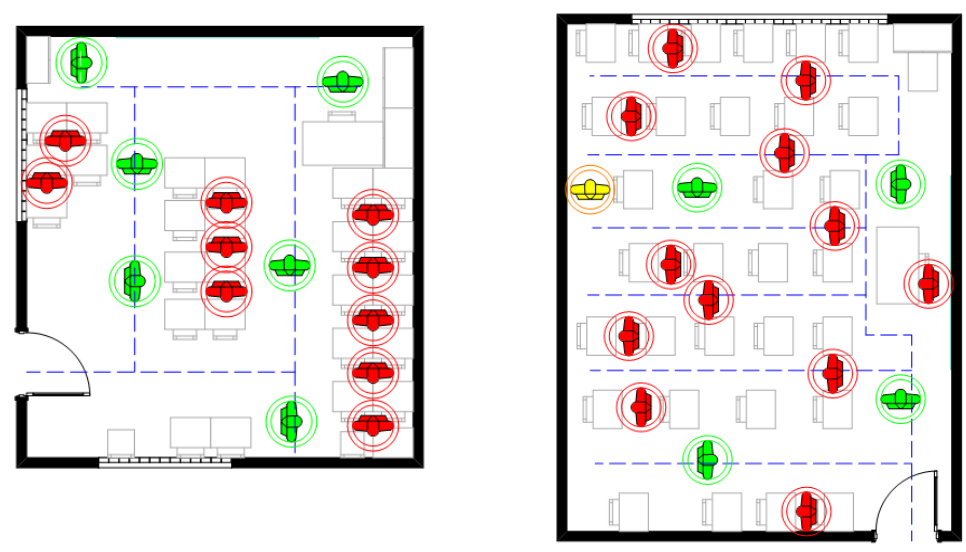

Fonte: Arquivo pesquisa

Fonte: Arquivo pesquisa.

Figura 18. Sala multiuso

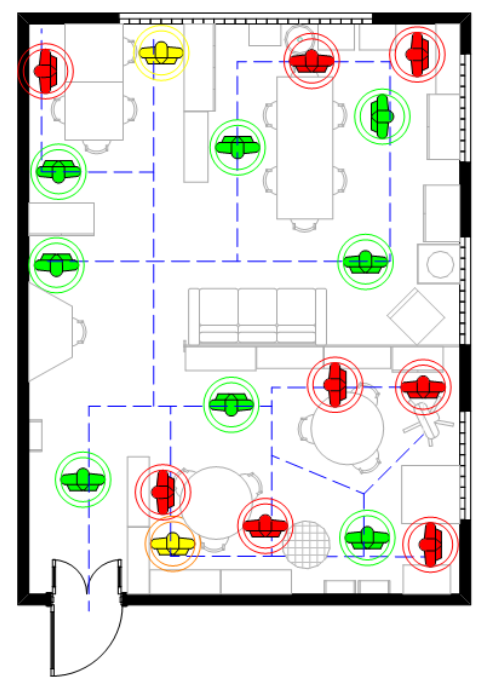

Fonte: Arquivo pesquisal.
Figura 19. Diretoria/secretaria

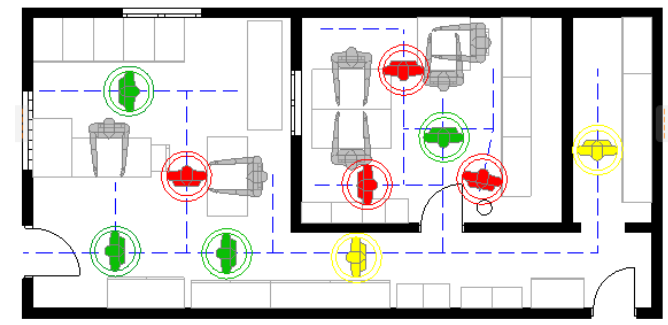

Fonte: Arquivo pesquisal.

Verifica-se que as duas salas de aulas são os ambientes que apresentam mais situações inadequadas de circulação. 


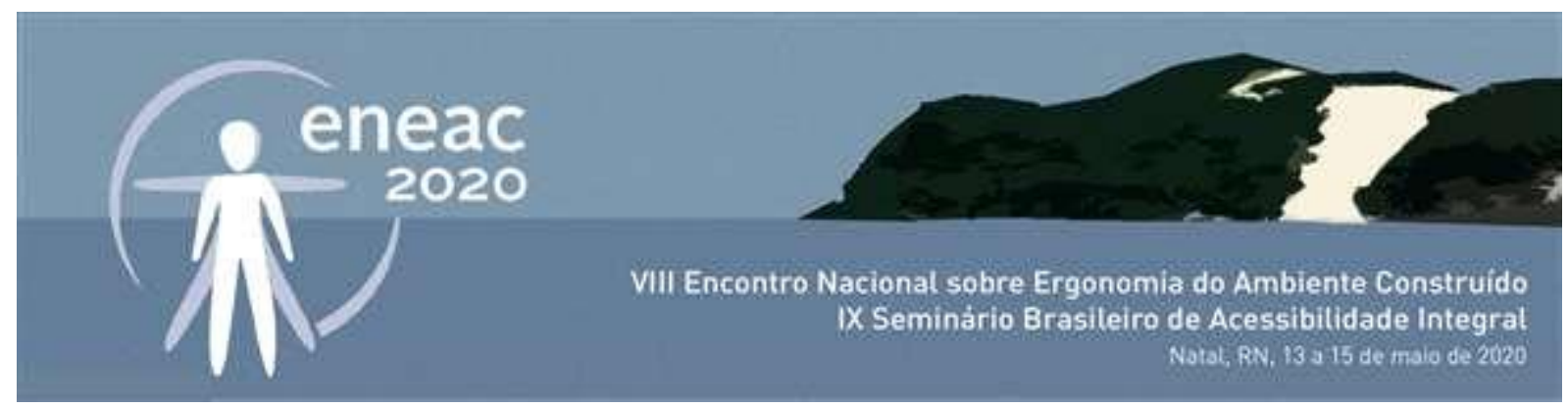

Gráfico 1. Sala do $4^{\circ}$ ano

Gráfico 2. Sala do $5^{\circ}$ ano

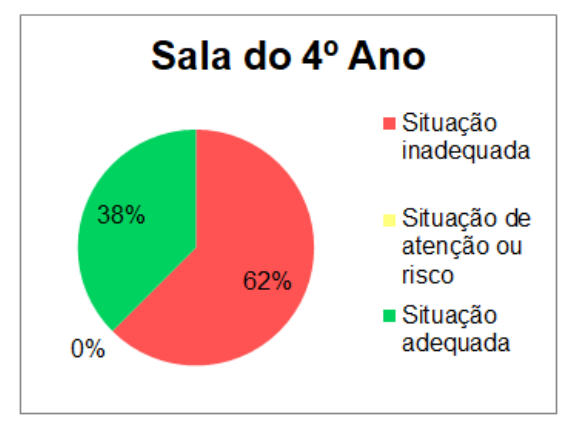

Fonte: Elaborado pelos autores

Gráfico 3. Sala Multiuso

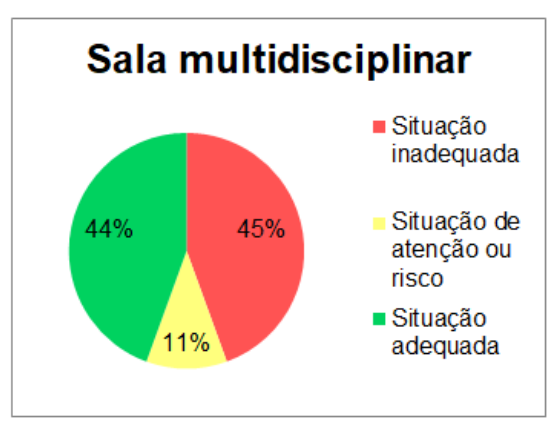

Fonte: Elaborado pelos autores

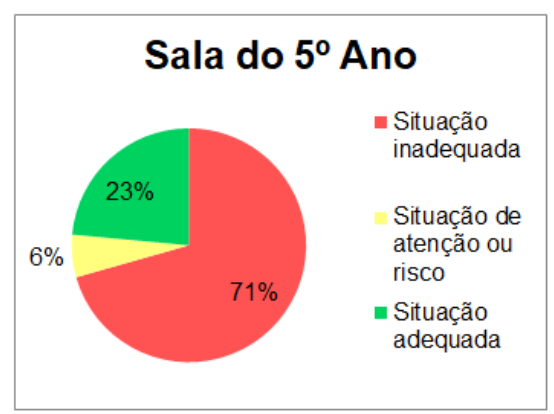

Fonte: Elaborado pelos autores.

Gráfico 4. Sala da secretaria/diretora

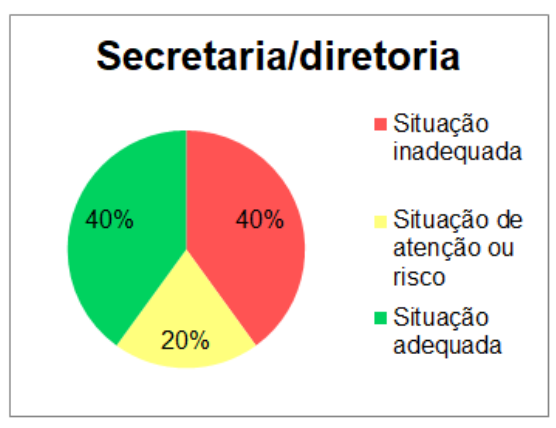

Fonte: Elaborado pelos autores.

\subsection{Percepção do ambiente}

A ferramenta de percepção utilizada foi o Poema dos Desejos, tendo a seguinte questão norteadora "Como você gostaria que fosse a sua escola nos aspectos físicos?". A aplicação se deu no dia 04/novembro, através da distribuição de folhas de papel nas salas de aulas do 4 ㅇ e 5 o ano (turno da tarde), dos EJA II e III (turno da noite) e para os funcionários presentes na escola. Por fim, 92 pessoas participaram. 


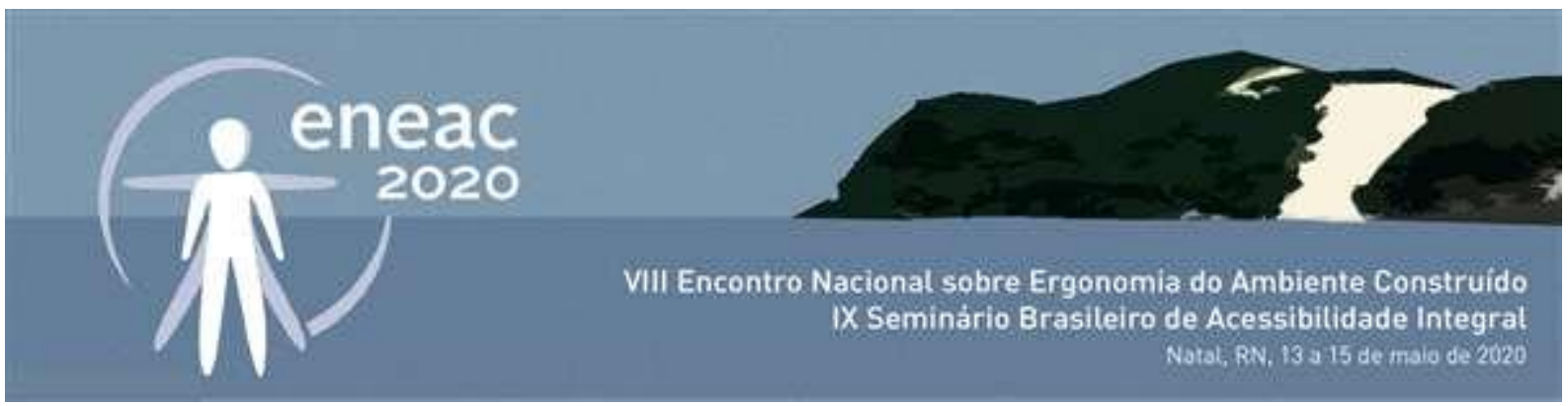

Gráfico 5: Gráfico Poema dos Desejos

FUNCIONÁRIOS (19)

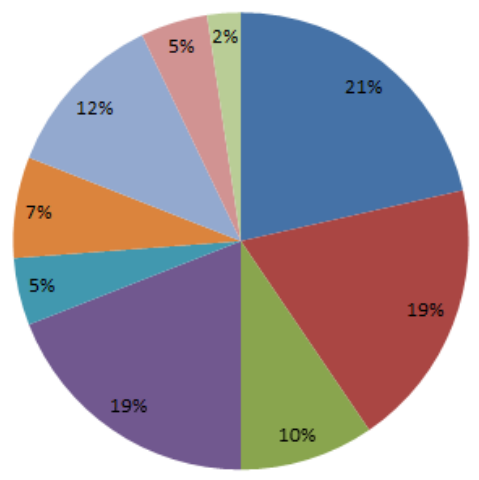

n Quadra (maior, com rede de proteşào e coberta)

- Setorizar os ecpaços

E Mas treas verdes
ALUNOS ADULTOS (41)

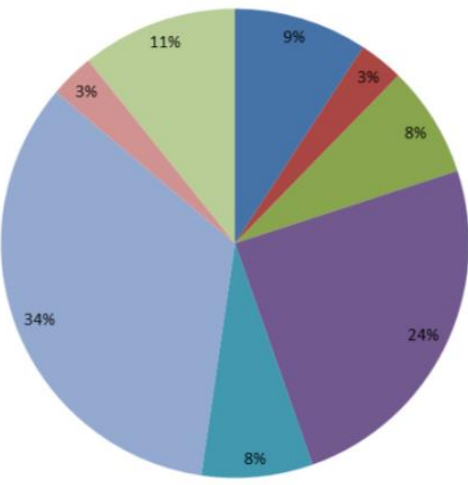

- infroestrutura basica do bonheiro

E Mobiliario do refeitorio mais confortaveis

= Mais diversidade de brinquedos no perquinho
ALUNOS CRIANÇAS (32)

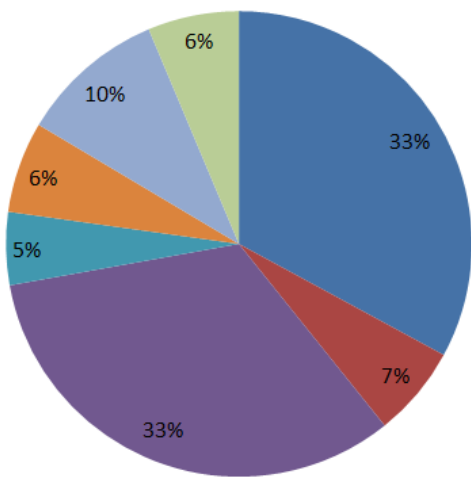

Me Morias nas salas de oulas

* Cozinha maior e mas arejada

II Pátio maior

Fonte: Elaborado pelos autores

As respostas expressas nos gráficos (Gráfico 5) representam as que apareceram com maior frequência em todas as três categorias de entrevistados. Entretanto, é importante considerar ter havido variações dentro das respostas citadas, por exemplo: em "melhorias nas salas de aula" os alunos criança indicaram a necessidade de computadores, enquanto os alunos adultos enfatizaram a urgência na melhoria do conforto dos mobiliários cadeira e mesa.

Além disso, tendo em vista que os alunos adultos estudam no período da noite, a questão da melhoria de iluminação foi praticamente unânime, estando esta questão também representada dentro da resposta "melhorias nas salas de aula". Outra resposta com comportamento semelhante foi a do "pátio maior" que, enquanto as crianças solicitaram mais brinquedos, os adultos citaram o desejo por mais bancos no espaço.

Entre os funcionários, é evidente a ênfase na necessidade de uma melhor setorização dos espaços, expressando o desejo por mais salas com tipos de usos específicos, por exemplo: sala de professores, biblioteca, sala de reunião. Tendo em vista que atualmente, essas atividades ocorrem simultaneamente em um mesmo espaço, provocando desconforto acústico e dificultando fluxos.

É possível perceber que em todos os grupos, as questões da quadra e do banheiro foram significativamente representadas, demonstrando serem os espaços mais precários da escola e consequentemente os que acumulam maior desejo por melhorias.

Sobre a ferramenta utilizada Poema dos Desejos, os autores se depararam com algumas barreiras no processo de aplicação. Tendo sido a escrita a linguagem utilizada, algumas crianças e adultos apresentaram dificuldade de se expressar, seja pela letra ilegível ou pelo domínio ainda precário do 


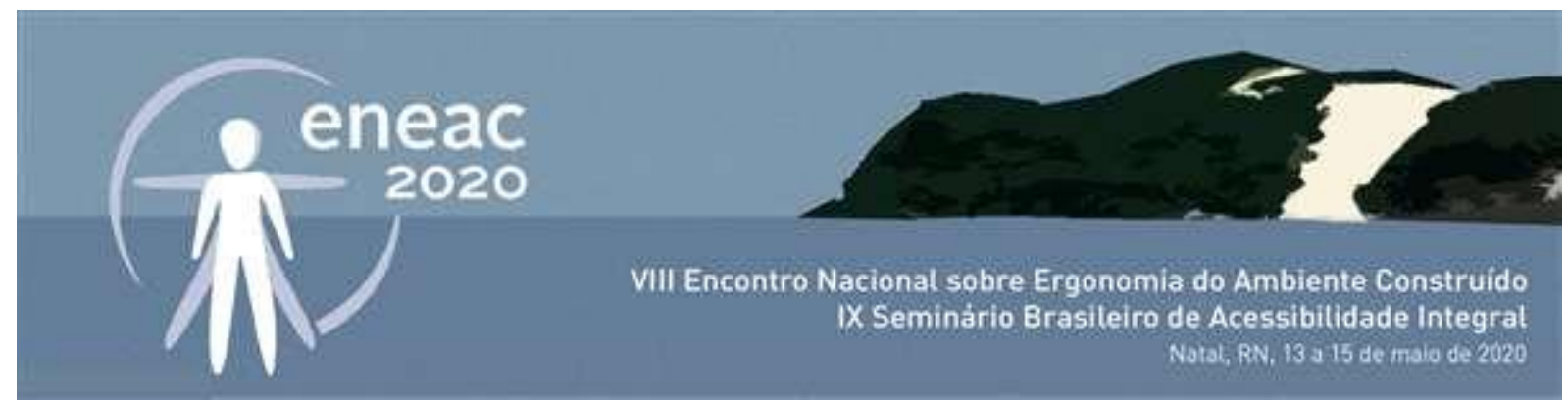

ato da escrita. Foi curioso perceber que, por mais que a pergunta norteadora fosse estimulando uma descrição de uma realidade desejada, o público adulto tendeu a listar locais problemáticos da escola, por vezes, não especificando em que aspecto exatamente desejava a melhoria. Enquanto isso, o grupo infantil indicou com mais clareza e detalhe quais os anseios, por vezes, descrevendo a motivação da escolha.

Em geral, as respostas dos 92 entrevistados foram complementares entre si, tendo sido a única distância a questão climática, pois apesar de unanimemente concordarem na necessidade de melhor climatização, alguns indicavam preferência por soluções naturais, enquanto outros desejavam mais equipamentos de refrigeração artificial.

\subsection{Diagnóstico e recomendações}

O quadro abaixo lista de forma didática as problemática percebidas e as respectivas recomendações elaboradas pelos autores. (Quadro 1).

Quadro 1 - Diagnóstico e recomendações

\begin{tabular}{|c|c|c|}
\hline Ambientes & Diagnóstico & Recomendações \\
\hline \multirow{3}{*}{$\begin{array}{c}\text { Sala de aula } 4 \\
\text { ano e EJA II }\end{array}$} & $\begin{array}{l}\text { Poucos espaços disponíveis para armazenamento } \\
\text { de materiais pedagógicos }\end{array}$ & $\begin{array}{l}\text { Substituição de mobiliários inutilizados } \\
\text { (cadeiras em excesso) por armários }\end{array}$ \\
\hline & $\begin{array}{l}\text { Circulação de alunos obstruída devido a layout } \\
\text { de carteiras de forma aglomeradas }\end{array}$ & Estudo de novo layout para a sala \\
\hline & Porta sem maçaneta & Substituição por maçaneta tipo alavanca \\
\hline \multirow{2}{*}{$\begin{array}{l}\text { Sala de aula } 5 \\
\text { ano e EJA III }\end{array}$} & $\begin{array}{l}\text { Maçaneta do tipo bola em desconformidade com } \\
\text { a NBR } 9050\end{array}$ & Substituição por maçaneta tipo alavanca \\
\hline & Corredores de circulação estreitos & $\begin{array}{l}\text { Estudo de novo layout para a sala, deixando } \\
\text { na sala somente as cadeiras necessárias }\end{array}$ \\
\hline \multirow{4}{*}{ Sala Multiuso } & $\begin{array}{l}\text { Ambiente sobrecarregado de funções e } \\
\text { mobiliários, obstruindo a circulação e } \\
\text { prejudicando a privacidade e ao acesso dos livros } \\
\text { disposto nas estantes da biblioteca }\end{array}$ & $\begin{array}{l}\text { Construção de novas salas para abrigarem as } \\
\text { diferentes funções }\end{array}$ \\
\hline & $\begin{array}{l}\text { Grade e porta com } 02 \text { folhas de abrir dificultam o } \\
\text { acesso fluído }\end{array}$ & $\begin{array}{l}\text { Substituir esquadria atual por modelo de } 01 \\
\text { folha de abrir com maçaneta alavanca }\end{array}$ \\
\hline & $\begin{array}{l}\text { Estantes de livros altas com difícil acesso para as } \\
\text { crianças }\end{array}$ & $\begin{array}{l}\text { Substituição do mobiliário considerando a } \\
\text { altura dos alunos }\end{array}$ \\
\hline & Piso irregular com algumas peças faltando & Manutenção do piso \\
\hline \multirow{3}{*}{ Secretaria } & Não possui conforto térmico & $\begin{array}{l}\text { Implantação de esquadrias para aproveitar a } \\
\text { ventilação natural ou implantação de ar } \\
\text { condicionado }\end{array}$ \\
\hline & $\begin{array}{l}\text { Fluxo interno constante, dificultando } \\
\text { desenvolvimento de atividades de gestão }\end{array}$ & $\begin{array}{l}\text { Acesso restrito aos funcionários, com } \\
\text { abertura de esquadria para atendimento de } \\
\text { pais e alunos }\end{array}$ \\
\hline & Armários obstruindo circulação & $\begin{array}{l}\text { Criação de um almoxarifado para armazenar } \\
\text { materiais pedagógicos }\end{array}$ \\
\hline \multirow{2}{*}{ Diretoria } & $\begin{array}{l}\text { Necessidade de adentrar a secretaria para } \\
\text { acessar espaço }\end{array}$ & Criação de acesso independente \\
\hline & Espaço sobrecarregado de mobiliários & $\begin{array}{l}\text { Criação de um almoxarifado para armazenar } \\
\text { materiais pedagógicos }\end{array}$ \\
\hline Geral & Padrão de iluminação abaixo da norma e com & Implantação de um novo sistema de \\
\hline
\end{tabular}




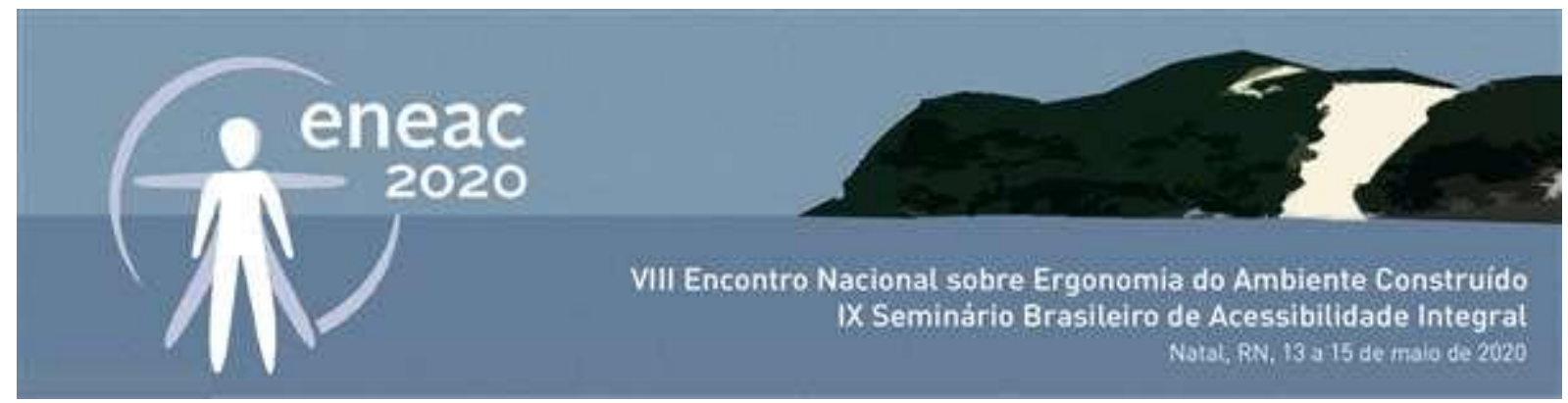

\begin{tabular}{|l|l}
\hline distribuição não uniforme no ambiente. & $\begin{array}{l}\text { iluminação que tenha uma padrão mais } \\
\text { uniforme }\end{array}$ \\
\cline { 2 - 3 } Padrão de ruído acima da norma & $\begin{array}{l}\text { Utilização de materiais com bom } \\
\text { desempenho acústico para absorver parte } \\
\text { dos ruídos }\end{array}$ \\
\hline Padrão de temperatura acima do confortável & $\begin{array}{l}\text { Inclusão de mais equipamentos de } \\
\text { refrigeração artificial ou aberturas zenitais e } \\
\text { novas esquadrias venezianas }\end{array}$ \\
\hline $\begin{array}{l}\text { Comunicação visual fora das recomendações da } \\
\text { NBR 9050:2015 }\end{array}$ & $\begin{array}{l}\text { Na parede, ao lado da porta, os nomes dos } \\
\text { ambientes devem estar em altura entre 1,20 } \\
\text { e 1,60m com sinalização em Braille }\end{array}$ \\
\cline { 2 - 3 } Inacessível para deficientes visuais & $\begin{array}{l}\text { Inclusão de piso tátil nos ambientes em } \\
\text { comum }\end{array}$ \\
\hline
\end{tabular}

Fonte: Elaborado pelos autores

\section{CONSIDERAÇÕES FINAIS}

Correlacionando a metodologia MEAC, com atenção especial aos usuários que diariamente se utilizam deste espaço para desenvolver suas atividades, inferimos que o ambiente construído encontra-se com necessidades de melhoria, principalmente relacionadas a conforto e a acessibilidade. Aponta-se que de maior importância seria a ampliação dos espaços úteis da instituição para comportar todo o programa de necessidades indicado pelos entrevistados, porém, paralelamente, há questões de menor escala e de mais fácil execução, que merecem atenção com urgência, como é o caso da reforma da quadra de esporte implantado rede de proteção e coberta, bem como melhorar a infraestrutura básica do banheiro. Conforme intencionado, a pesquisa será disponibilizada para a instituição de ensino estudada a fim de auxiliar no processo de viabilização de verbas para a realização das recomendações sugeridas.

\section{REFERÊNCIAS}

ASSOCIAÇÃO BRASILEIRA DE NORMAS TÉCNICAS. NBR 9.050: Acessibilidade de pessoas portadoras de deficiências e edificações, espaço, mobiliário e equipamentos urbanos. Rio de Janeiro, 2015.

ASSOCIAÇÃO BRASILEIRA DE NORMAS TÉCNICAS. NBR 10152: Nível de ruído para conforto acústico. Rio de Janeiro, 2000.

MACHADO, Ernani; AZEVEDO, Gisele; ABDALLA, Gustavo. A Importância do Olhar dos Usuários em Ambientes da Arquitetura Hospitalar: uma aplicação do Poema dos Desejos. Anais do 2ㅇ Simpósio Brasileiro de Qualidade do Projeto no Ambiente Construído e X Workshop Brasileiro de Gestão do Processo de Projeto na Construção de Edifícios, Rio de Janeiro, PROARQ/FAU/UFRJ e PPG-IAU USP, Novembro de 2011.

NR, Norma Regulamentadora Ministério do Trabalho e Emprego. NR-17: Ergonomia. 2018.

NHO, Norma de Higiene Ocupacional do Ministério. NHO-11: Avaliação dos níveis de iluminamento em ambientes internos de trabalho. São Paulo, 2018.

PANERO, Julius; ZELNIK, M. Dimensionamento Humano para Espaços Interiores. 8ª Ed. México, D.F., Gustavo Gili, 2008.

VILLAROUCO, Vilma. Construindo uma metodologia de avaliação ergonômica do ambiente. In: Anais do XV Congresso Brasileiro de Ergonomia - ABERGO, Bahia, 2008. 